Article

\title{
Testing a Microarray to Detect and Monitor Toxic Microalgae in Arcachon Bay in France
}

\author{
Jessica U. Kegel ${ }^{1}{ }^{1}$, Yolanda Del Amo ${ }^{2}$, Laurence Costes ${ }^{2}$ and Linda K. Medlin ${ }^{1, *}$ \\ 1 Marine Biological Association of the United Kingdom, The Laboratory, Citadel Hill, Plymouth, \\ PL1 2PB, UK \\ 2 Université Bordeaux 1, UMR CNRS EPOC 5805, Station Marine d'Arcachon, \\ 2 rue du Prof. Jolyet F 33120 Arcachon, France; \\ E-Mails: y.delamo@epoc.u-bordeaux1.fr (Y.D.A.); 1.costes@epoc.u-bordeaux1.fr (L.C.) \\ * Authors to whom correspondence should be addressed; E-Mails: kegel @ obs-banyuls.fr (J.U.K.); \\ lkm@mba.ac.uk (L.K.M.); Tel.: +44-1752-633207 (L.K.M.); Fax: +44-1752-633102 (L.K.M.).
}

Received: 27 November 2012; in revised form: 24 January 2013 / Accepted: 26 February 2013 / Published: 5 March 2013

\begin{abstract}
Harmful algal blooms (HABs) occur worldwide, causing health problems and economic damages to fisheries and tourism. Monitoring agencies are therefore essential, yet monitoring is based only on time-consuming light microscopy, a level at which a correct identification can be limited by insufficient morphological characters. The project MIDTAL (Microarray Detection of Toxic Algae) — an FP7-funded EU project-used rRNA genes (SSU and LSU) as a target on microarrays to identify toxic species. Furthermore, toxins were detected with a newly developed multiplex optical Surface Plasmon Resonance biosensor (Multi SPR) and compared with an enzyme-linked immunosorbent assay (ELISA). In this study, we demonstrate the latest generation of MIDTAL microarrays (version 3) and show the correlation between cell counts, detected toxin and microarray signals from field samples taken in Arcachon Bay in France in 2011. The MIDTAL microarray always detected more potentially toxic species than those detected by microscopic counts. The toxin detection was even more sensitive than both methods. Because of the universal nature of both toxin and species microarrays, they can be used to detect invasive species. Nevertheless, the MIDTAL microarray is not completely universal: first, because not all toxic species are on the chip, and second, because invasive species, such as Ostreopsis, already influence European coasts.
\end{abstract}


Keywords: oligonucleotide microarrays; molecular monitoring; harmful algal blooms; HABs; toxic microalgae; 18S/28S ribosomal RNA; LSU/SSU; RNA hybridization; environmental water samples

\section{Introduction}

Worldwide every year, fisheries, aquaculture, human health and tourism are threatened by harmful algal blooms (HABs) in marine, brackish, as well as continental waters. Although most phytoplankton species are benign, about $2 \%$ of them can cause harm through the production of toxins or by an excessive accumulated biomass, which can affect co-occurring organisms and alter food-web dynamics [1,2]. In addition to the ecological and economic damages, public health is also at risk: the consumption of shellfish that have fed on toxic phytoplankton and accumulated toxins, and exposure to the aerosols of HAB toxins can cause illness or even mortality. Depending on the species, it can take only a few toxic cells per liter to poison shellfish and make them unsuitable for human consumption [3]. Monitoring of microalgae is therefore required by all countries with a marine coastline. $\mathrm{HAB}$ monitoring programs are currently based on cells identified and counted by light microscopy and on the mouse bioassay for detecting biotoxins. The mouse bioassay for the detection of phytoplankton toxins in shellfish has recently been banned by the European Commission (July 2011), and there is a mandatory replacement by chemical methods (Liquid Chromatography-Mass Spectrometry, LC-MS) in the next three years.

However, the effectiveness of monitoring programs using light microscopic identification is limited by the fact that it is time consuming and that morphology, as determined by light microscopy, may be insufficient to give definitive species and toxin attribution. Thus, there is a need to implement molecular methods to ensure a fast and reliable species identification. Monitoring for toxic species using molecular techniques advances the state of knowledge for detection of harmful species because more samples can be analyzed in a shorter time period and with greater accuracy. Within the actual context of the dramatic decreasing number of taxonomic experts of phytoplankton [4], which are, notwithstanding, essential for other ecological studies, such techniques offer important advances. This is of particular interest for potentially toxic algae, because the difficulty in determining their exact identification by using light microscopy can have disastrous consequences for human health. Microarrays offer a near real-time ecosystem analysis and offer broader ecological interpretation of how key species, such as toxic algae, can extend their geographical distribution with climate change or can become invasive after introduction from remote areas [5]. Microarrays offer the most expeditious method to have high sample throughput with highly accurate species detection, in a universal approach [6-8]. In the FP7 EU project, MIDTAL (Microarrays for the Detection of Toxic Algae), an earlier protocol for detection of toxigenic microalgae by Gescher et al. [9] was optimized. Microarrays (as phylochips) detect multiple species simultaneously using species-specific probes that have been applied primarily for the detection of bacteria [10-13]. At present, 140 probes for various toxic algal species at various taxonomic levels are spotted onto the current generation of the MIDTAL microarray. As part of the MIDTAL project, the primary goal was to be able to infer cell numbers from the molecular signal to 
provide an early warning system for toxic algae. Because the MIDTAL microarray is a universal array that can be used globally, it offers a real possibility of detecting invasive species, especially in view of global warming where warm temperate species are moving northward, e.g., Gamberiodiscus.

In this study, we show the effectiveness of using microarrays for the detection of toxic algae and its combination with toxin detection. We compare these results with light microscopy data from a regular French monitoring network of toxic phytoplankton. The microarray used in this study represents the third generation array developed within the EU-MIDTAL project. In generation one, probes (18-22 nt) developed for Fluorescent in situ Hybridization (FISH) were used directly; in generation two, these FISH probes, and any newly designed probes, were lengthened to 25 or more nt; in generation three, an additional poly-T spacer to lift the probes farther above the surface was tested and optimized (Figure 1). At each generation, minor changes in the hybridization protocol were made and a final optimized protocol can be found in Lewis et al. [14].

Figure 1. Scheme of the development of the MIDTAL microarray. The scheme pictures the different microarray generations with its different probes, tests and enhancements of protocols (RNA and hybridization). (* Higher temperature during 3rd washing step).

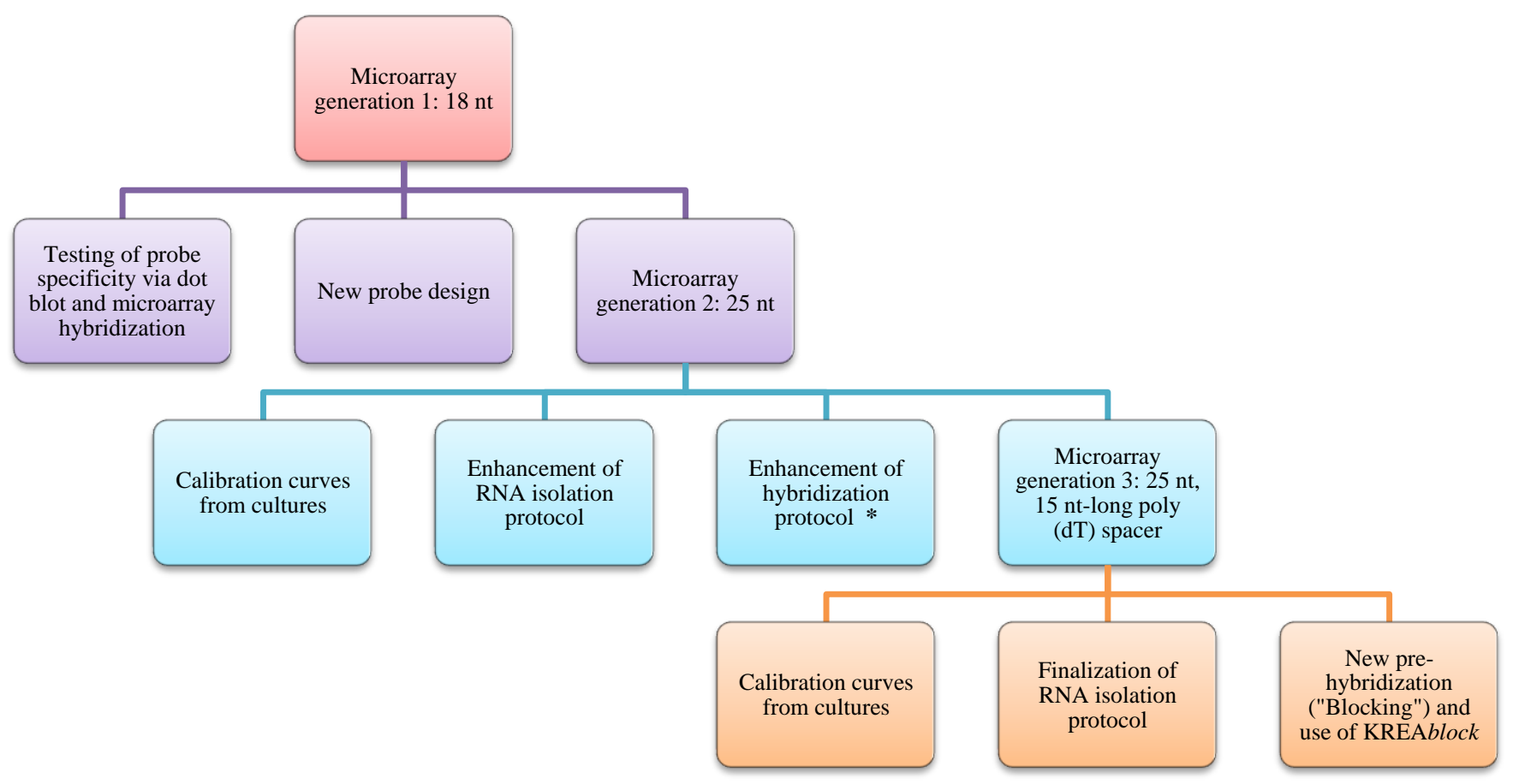

\section{Experimental Section}

\subsection{Field Sampling}

In 2011, water samples from the sub-surface (1 $\mathrm{m}$ depth) were collected at Arcachon Bay in France (Figure 2) between July and October for microarray analysis (Table 1). The sampling site termed Tès $\left(1^{\circ} 10^{\prime} 00 \mathrm{~W}, 44^{\circ} 40^{\prime} 00 \mathrm{~N}\right)$, is directly located in front of the town of Arcachon inside the bay. Data of toxic, harmful, and other phytoplankton abundances is provided by IFREMER (Ifremer/Quadrige ${ }^{2} /$ Rephy DATA) from the paired station named Teychan (1.5 km from Tès). Cell counts were done as previously described by Medlin and Schmidt [15] and Kegel et al. [16]. 
Table 1. Information about field samples taken at Arcachon Bay like sample name, sample date, filtered volume, total extracted RNA and degree of labeling (DoL).

\begin{tabular}{ccccc}
\hline Sample name & Sample date & Volume filtered $(\mathbf{L})$ & Total RNA extracted $(\boldsymbol{\mu g})$ & DoL \\
\hline 1A & $24 / 07 / 2011$ & 3.3 & 7.46 & 2.2 \\
2A & $08 / 08 / 2011$ & 3.0 & 9.48 & 2.0 \\
3A & $22 / 08 / 2011$ & 3.3 & 9.52 & 1.9 \\
4A & $04 / 10 / 2011$ & 3.25 & 10.66 & 2.2 \\
6A & $20 / 10 / 2011$ & 3.3 & 13.82 & 2.2 \\
\hline
\end{tabular}

Figure 2. Sampling sites in Arcachon Bay (France): the station Tès (Teychan).

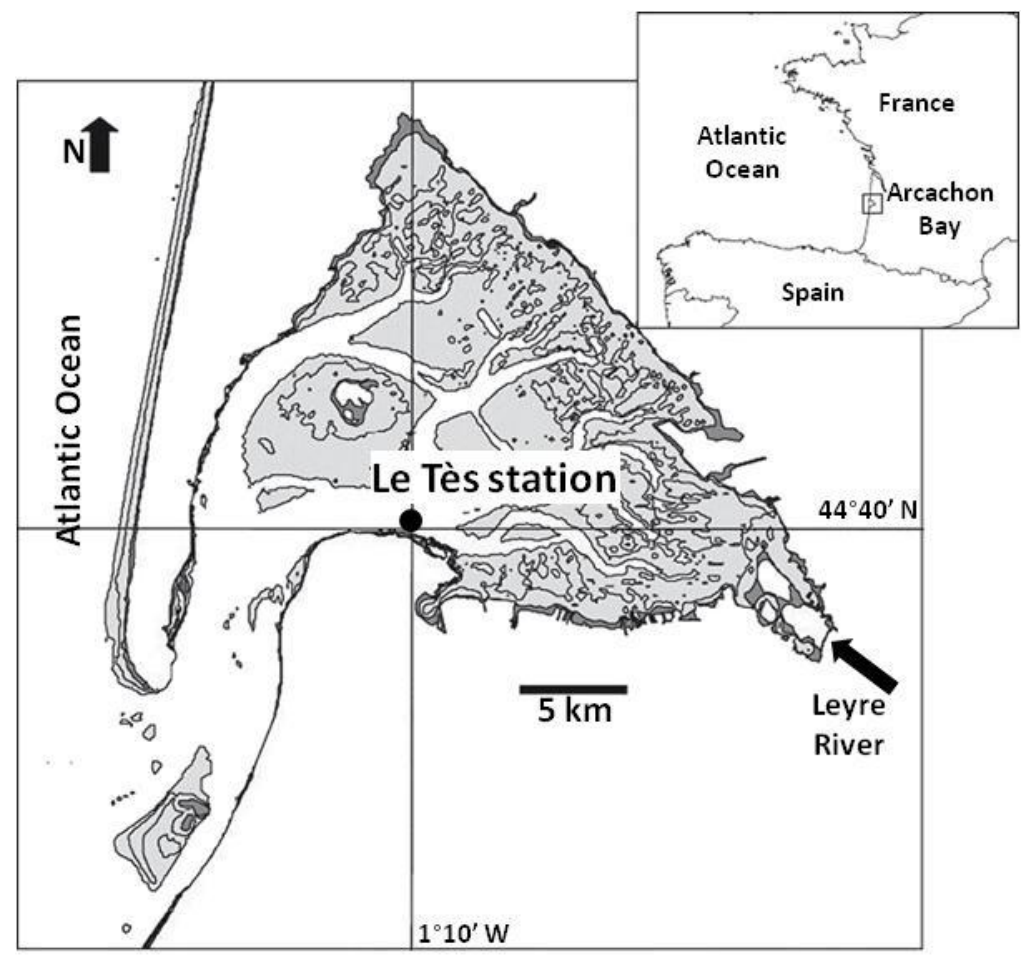

For the microarray analysis, a minimum of three liters (Table 1) were filtered onto $3 \mu \mathrm{m}$ nitrocellulose filters $(47 \mathrm{~mm})$ in triplicate. For each sampling date, the first and second replicated filter was transferred into cryogenic vials containing $1 \mathrm{~mL}$ of TRI Reagent (Sigma-Aldrich). Those samples were snap frozen and stored at $-80{ }^{\circ} \mathrm{C}$ until further process for RNA extraction. Toxicity was measured by one of the Partners (Queens University Belfast, UK) with a newly developed multiplex optical Surface Plasmon Resonance biosensor (Multi SPR) in parallel with the enzyme-linked immunosorbent assay (ELISA) [17]. The target toxins are domoic acid (DA) for amnesic shellfish poisoning (ASP), okadaic acid (OA) and dinophysistoxins (DTXs) for diarrhetic shellfish poisoning (DSP) and saxitoxin (STX) for paralytic shellfish poisoning (PSP) toxin analogs. Therefore, the third replicated filter was transferred into cryogenic vials without TRI Reagent and sent frozen to Queens University Belfast who was responsible for the toxin measurements.

\subsection{RNA Extraction}

RNA extraction was done with minor changes to that presented in Kegel et al. [16]. Briefly, acid-washed glass beads $(300 \mu \mathrm{m})$ and 500,000 cells of Dunaliella tertiolecta-strain UIO226 (stored in 
TRI Reagent) as a control were added to the samples and the samples were bead-beaten twice for $1 \mathrm{~min}$ at 4,800 oscillations/min (BioSpec Mini Bead Beater). Cell-TRI Reagent mixture was transferred into a new microcentrifuge tube, vortexed for $15 \mathrm{~s}$ and left to stand at room temperature (RT) for $10 \mathrm{~min}$. After another $15 \mathrm{~s}$ of vortexing, samples were incubated at $60{ }^{\circ} \mathrm{C}$ for $10 \mathrm{~min}$ in a Thermoshaker at maximum speed. Samples were vortexed again for $15 \mathrm{~s}$ and then transferred into pre-spun Phase Lock Gel Heavy $2 \mathrm{~mL}$ tubes (5 Prime; 12,000 g for $30 \mathrm{~s}$ ). After the addition of $100 \mu \mathrm{L}$ of 1-bromo-3-chloropropane (BCP) to the samples, the tubes were shaken thoroughly for $15 \mathrm{~s}$. Samples were incubated at RT for $5 \mathrm{~min}$ and centrifuged $(12,000 \times g)$ for $15 \mathrm{~min}$ at $4{ }^{\circ} \mathrm{C}$. The upper phase was mixed gently with $200 \mu \mathrm{L}$ chloroform and centrifuged $(12,000 \times g)$ for 2 min at $4{ }^{\circ} \mathrm{C}$. The aqueous phase was then transferred to a fresh $2 \mathrm{~mL}$ RNase-free tube. Equal volumes of isopropanol were added, vortexed for $15 \mathrm{~s}$ and incubated for one hour at $-20{ }^{\circ} \mathrm{C}$. After incubation, samples were centrifuged $(12,000 \times g)$ for $15 \mathrm{~min}$ at $4{ }^{\circ} \mathrm{C}$. Supernatant was quickly removed and pellets were washed three times with $1 \mathrm{~mL}$ ethanol (75\%): ethanol was added, vortexed for $5 \mathrm{~s}$, centrifuged $(12,000 \times g)$ for $10 \mathrm{~min}$ at $4{ }^{\circ} \mathrm{C}$, and supernatant carefully removed. Following the third wash, the supernatant was completely removed and the pellet was air-dried for $5 \mathrm{~min}$. The pellet was dissolved in $100 \mu \mathrm{L}$ of RNase-free water. To get rid of TRI Reagent residuals, samples were precipitated with 0.5 volume of 7.5 $\mathrm{M} \mathrm{NH}_{4} \mathrm{Ac}$ and 2 volumes of ice-cold ethanol (absolute, stored at $-20{ }^{\circ} \mathrm{C}$ ). The mixture was vortexed and incubated at $-80{ }^{\circ} \mathrm{C}$ for $1.5 \mathrm{~h}$. Immediately after incubation, samples were centrifuged at $4{ }^{\circ} \mathrm{C}$ and max. speed for $20 \mathrm{~min}$. The supernatant was removed; the pellet was washed in $500 \mu \mathrm{L}$ of $70 \%$ ice-cold ethanol (stored at $-20^{\circ} \mathrm{C}$ ) and centrifuged for 5 min at max. speed. The washing step was repeated and the pellet was air-dried for 30-60 min. The RNA was re-suspended in $50 \mu \mathrm{L}$ nuclease-free water and its concentration and integrity was measured by NanoVue spectrophotometer (GE Healthcare) and Agilent Bioanalyzer 2100 (Agilent Biotechnologies). Samples were snap-frozen in liquid nitrogen and stored at $-80{ }^{\circ} \mathrm{C}$ until further use.

\subsection{RNA Labeling and Fragmentation}

The PlatinumBright Infrared Labeling Kit from KREATECH (Amsterdam, Netherlands) was used to label $1.5 \mu \mathrm{g}$ RNA of field sample using $2 \mu \mathrm{L}$ ULS dye and $2 \mu \mathrm{L} 10 \times$ labeling solution in a total volume of $20 \mu \mathrm{L}$. Samples were labeled by incubation for $30 \mathrm{~min}$ at $85{ }^{\circ} \mathrm{C}$. After incubation, samples were placed on ice and spun down and then purified with KREApure columns (KREATECH) according to the manufacturer's instructions. Concentration and incorporation of the dye was measured by a NanoVue (GE Healthcare). The DoL (degree of labeling) was calculated and was between 1.9 and $2.2 \%$ (Table 1). RNA was fragmented by adding 1/10 volume of RNA fragmentation buffer (100 mM $\mathrm{ZnCl}_{2}$ in $100 \mathrm{mM}$ Tris-HCL, $\mathrm{pH} \mathrm{7.0)}$ and an incubation of $15 \mathrm{~min}$ at $70{ }^{\circ} \mathrm{C}$. The reaction was stopped with the addition of $1 / 10$ volume of $0.5 \mathrm{M}$ EDTA $(\mathrm{pH} 8.0)$ and the samples were placed on ice. The RNA was fragmented to reduce the effect of the secondary structure on the accessibility of the probe. Despite this fragmentation, we still have heterogeneous probe sensitivity, which reflects the influence of the secondary structure and we can only partially overcome this by fragmenting the RNA to remove the strongest secondary structure formations. 


\subsection{Microarray Design}

Probe design was done with the open software package ARB [18]. All oligonucleotides including the positive and negative controls were synthesized by Thermo Fisher Scientific (Ulm, Germany) with a C6 aminolink at the 5' end of the molecule. The probes had a length between 18 and 25 nt and a 15 nT-long poly (dT) tail following the $\mathrm{NH}_{2}$ link at the 5' end. Table 2 shows a list of the probes and their targets. The complete hierarchy for each probe can be found in the GPR-Analyzer which is available online at http://folk.uio.no/edvardse/gpranalyzer. The probe sequences are patent pending and a commercial kit will soon be available from Kreatech containing the array and all reagents for hybridization. Epoxy-coated slides (Genetix or Schott) of MIDTAL version 3.2 were printed using a pin printer VersArray ChipWriter Pro (Bio-Rad Laboratories GmbH, Munich, Germany) and split pins (Point Technologies, Inc., CO) as described by Kegel et al. [16]. One array contained 136 different probes and 4-8 replicates, as well as three negative (NEGATIVE1_dT, NEGATIVE2_dT, NEGATIVE3_dT), one positive control (TBP = TATA-box binding protein), Poly-T-Cy5 (spotting control), and two internal controls (DunGS02_25_dT and DunGS05_25_dT for Dunaliella tertiolecta) (MIDTAL ver3.2). After spotting, slides were incubated for $30 \mathrm{~min}$ at $37{ }^{\circ} \mathrm{C}$ and then stored at $-20{ }^{\circ} \mathrm{C}$.

Printing of MIDTAL slides version 3.3 was done by Scienion AG using a sciFlexarrayer S11 and epoxy-coated slides from Genetix. One array contained eight replicates of 140 different probes including the seven controls stated above. After printing, the slides were transferred to a $75 \%$ humidity chamber, kept there overnight at RT, and stored afterwards in a sealed aluminum bag refilled with $\operatorname{argon}$ at $4{ }^{\circ} \mathrm{C}$.

Table 2. Summary of probes designed or modified from published FISH probes and used to form the third generation of the MIDTAL microarray, including the targeted species, and whether it was made from the $18 \mathrm{~S}$ or $28 \mathrm{~S}$ rRNA gene. Probe sequences are not provided because the microarray is patent pending and will soon be commercially available from Kreatech, Amsterdam, The Netherlands. A complete taxonomic ordering of the probes can be seen in the GPR-Analyzer program and the MIDTAL hierarchy file that comes with that program.

\begin{tabular}{llc}
\hline Probe Name & Targeted Taxon & Gene \\
\hline Controls & & \\
DunGS02_25_dT & Dunaliella spp. & $18 \mathrm{~S}$ \\
DunGS05_25_dT & Dunaliella spp. & $18 \mathrm{~S}$ \\
Higher group-level probes & & \\
EukS_328_25_dT & Eukaryotes & $18 \mathrm{~S}$ \\
EukS_1209_25_dT & Eukaryotes & $18 \mathrm{~S}$ \\
HeteroS01_25_dT & Heterokonta & $18 \mathrm{~S}$ \\
PrymS01_25_dT & Prymnesiophyta & $18 \mathrm{~S}$ \\
Class-level probes & & $18 \mathrm{~S}$ \\
PrymS03_25_dT & Prymnesiophyceae & $18 \mathrm{~S}$ \\
DinoB_25_dT & Dinophyceae (incl. Apicomplexa) & $18 \mathrm{~S}$ \\
DinoE12_25_dT & Dinophyceae (incl. Apicomplexa) &
\end{tabular}


Table 2. Cont.

\begin{tabular}{|c|c|c|}
\hline \multicolumn{3}{|l|}{ Clade-level probes } \\
\hline DphyexacutaFS01_25_dT & Dinophysiaceae (Dinophysis + Phalacroma) & $18 \mathrm{~S}$ \\
\hline DphyFS02_25_dT & Dinophysiaceae (Dinophysis + Phalacroma) & $18 \mathrm{~S}$ \\
\hline PdeliD02_25_dT & P. delicatissima all clades & $28 \mathrm{~S}$ \\
\hline Clade 01new_25_dT & Prymnesium B1 clade & $18 \mathrm{~S}$ \\
\hline Clade01old_25_dT & Prymnesium & $18 \mathrm{~S}$ \\
\hline ProroPKD01_25_dT & Prorocentrum planktonic clade & $28 \mathrm{~S}$ \\
\hline ProroFPS01 & Prorocentrum planktonic clade & $18 \mathrm{~S}$ \\
\hline ProroFBS02_25_dT & Prorocentrum benthic clade & $18 \mathrm{~S}$ \\
\hline ProroFBS01 & Prorocentrum benthic clade & $18 \mathrm{~S}$ \\
\hline \multicolumn{3}{|l|}{ Genus-level probes } \\
\hline PsnGS01_25_dT & Pseudo-nitzschia & $18 \mathrm{~S}$ \\
\hline PsnGS02_25_dT & Pseudo-nitzschia + Fragilariopsis & $18 \mathrm{~S}$ \\
\hline PSN+FRAGS02-25new_dT & Pseudo-nitzschia + Fragilariopsis & $18 \mathrm{~S}$ \\
\hline PSN no pungens_25_dT & Pseudo-nitzschia no pungens & $18 \mathrm{~S}$ \\
\hline PSN + some Frags_25_dT & Pseudo-nitzschia + some Fragilariopsis & $18 \mathrm{~S}$ \\
\hline KareGD01_25_dT & Karenia & $28 \mathrm{~S}$ \\
\hline AlexGD01_25_dT & Alexandrium & $28 \mathrm{~S}$ \\
\hline DphyGD01_25_dT & Dinophysis in part & $28 \mathrm{~S}$ \\
\hline DphyGD02_25_dT & Dinophysis & $28 \mathrm{~S}$ \\
\hline PschGS01_25_dT & Pseudochattonella (genus) & $18 \mathrm{~S}$ \\
\hline PschGS04_25_dT & Pseudochattonella (genus) & $18 \mathrm{~S}$ \\
\hline PschG05_25_dT & Pseudochattonella (genus) & $18 \mathrm{~S}$ \\
\hline DphyGS01_25_dT & Dinophysis genus sensu stricto & $18 \mathrm{~S}$ \\
\hline DphyGS02_25_dT & Dinophysis genus sensu stricto & $18 \mathrm{~S}$ \\
\hline DphyGS03_25_dT & all Dinophysis and Phalacroma & $18 \mathrm{~S}$ \\
\hline DphyGS04_25_dT & all Dinophysis & $18 \mathrm{~s}$ \\
\hline KargeD01_25_dT & Karlodinium genus & $28 \mathrm{~S}$ \\
\hline AzaGD01_dT & Azadinium genus & $28 \mathrm{~S}$ \\
\hline AzaGD03_dT & Azadinium genus & $28 \mathrm{~S}$ \\
\hline AzaGS01_dT & Azadinium genus & $18 \mathrm{~S}$ \\
\hline AzaGS02_dT & Azadinium genus & $18 \mathrm{~S}$ \\
\hline \multicolumn{3}{|l|}{ Species-level probes } \\
\hline AtamaS01_25_dT & Alexandrium NA,WE,TA, species complex & $18 \mathrm{~S}$ \\
\hline AminuS01_25_dT & Alexandrium minutum & $18 \mathrm{~S}$ \\
\hline ATNA_D01_25_dT & A. tamarense (North America) & $28 \mathrm{~S}$ \\
\hline ATNA_D02_25_dT & A. tamarense (North America) & $28 \mathrm{~S}$ \\
\hline ATTA_D01_25_dT & A. tamarense (Temperate Asian) & $28 \mathrm{~S}$ \\
\hline AostD01_25_dT & A. ostenfeldii & $28 \mathrm{~S}$ \\
\hline AostS02_25_dT & A. ostenfeldii & $18 \mathrm{~S}$ \\
\hline CpolyS01_25_dT & Chrysochromulina polylepis & $18 \mathrm{~S}$ \\
\hline PparvD01_25_dT & Prymnesium parvum & $28 \mathrm{~S}$ \\
\hline Prymparv01_25_dT & Prymnesium parvum & $18 \mathrm{~S}$ \\
\hline KbreD03_25_dT & Karenia mikimotoi and brevis & $28 \mathrm{~S}$ \\
\hline KbreD04_25_dT & K. mikimotoi and brevis & $28 \mathrm{~S}$ \\
\hline
\end{tabular}


Table 2. Cont.

\begin{tabular}{|c|c|c|}
\hline KmikiD01_25_dT & K. mikimotoi & $28 \mathrm{~S}$ \\
\hline KbreD05_25 & K. brevis & $28 \mathrm{~S}$ \\
\hline LSKbre0548A25_dT & K. mikimotoi and brevis & $28 \mathrm{~S}$ \\
\hline KmGcS06_25_dT & K. mikimotoi, Gymnodinium catenatum, cf. Chatonella sp. & $18 \mathrm{~S}$ \\
\hline KbreD03c_25_dT & Competitor K. mikimotoi and brevis & $18 \mathrm{~S}$ \\
\hline KbreD04_25c_dT & Competitor K. mikimotoi and brevis & $28 \mathrm{~S}$ \\
\hline SSKbre1448A25_dT & $K$. brevis & $18 \mathrm{~S}$ \\
\hline SSKbre1448A25c_dT & K. brevis & $18 \mathrm{~S}$ \\
\hline LSKBre0548A25c_dT & K. brevis & $28 \mathrm{~S}$ \\
\hline SSGcat0826A27_dT & Gymnodinium catenatum & $18 \mathrm{~S}$ \\
\hline LSGcat0270A24_dT & G. catenatum & $28 \mathrm{~S}$ \\
\hline GcateS01_25_dT & G. catenatum & $18 \mathrm{~S}$ \\
\hline KveneD01_25_dT & Karlodinium veneficum & $28 \mathrm{~S}$ \\
\hline KveneD02_25_dT & Karlodinium veneficum & $28 \mathrm{~S}$ \\
\hline KveneD03_25_dT & Karlodinium veneficum & $28 \mathrm{~S}$ \\
\hline KveneD04_25_dT & Karlodinium veneficum & $28 \mathrm{~S}$ \\
\hline KveneD05_25_dT & Karlodinium veneficum & $28 \mathrm{~S}$ \\
\hline KveneD06_25_dT & Karlodinium veneficum & 28 \\
\hline PlimaS01_25_dT & Prorocentrum lima & $18 \mathrm{~S}$ \\
\hline PlimaFD01_2_dT5 & P. lima & $28 \mathrm{~S}$ \\
\hline PmicaD02_25_dT & P. micans & $28 \mathrm{~S}$ \\
\hline PminiD01_25_dT & P. minimum & $28 \mathrm{~S}$ \\
\hline PmacuS01 & P. maculosum and belizeanum & $18 \mathrm{~S}$ \\
\hline PmacuD01 & P. maculosum & $28 \mathrm{~S}$ \\
\hline PmacuD02 & P. maculosum & $28 \mathrm{~S}$ \\
\hline PrathD01 & P. rathymum and mexicanum & $28 \mathrm{~S}$ \\
\hline PrathD02 & P. rathymum and mexicanum & $28 \mathrm{~S}$ \\
\hline DacumiD02_25_dT & Dinophysis acuminata, dens and sacculus & $28 \mathrm{~S}$ \\
\hline DacutaD02_25_dT & Dinophysis acuta and fortii & $28 \mathrm{~S}$ \\
\hline DacumiS01_25_dT & Dinophysis acuminata & $18 \mathrm{~S}$ \\
\hline DacutaS01_25_dT & Dinophysis acuta & $18 \mathrm{~S}$ \\
\hline DnorvS01_25_dT & Dinophysis norvegica & $18 \mathrm{~S}$ \\
\hline PausserD01_25_dT & Pseudo-nitzschia australis and seriata & $28 \mathrm{~S}$ \\
\hline PmulausD01_25_dT & P. australis and multistriata & $28 \mathrm{~S}$ \\
\hline PcaserausD02_25_dT & P. australis, seriata, deli2 & $28 \mathrm{~S}$ \\
\hline PcaserausD03_25_dT & P. australis, seriata, calliantha & $28 \mathrm{~S}$ \\
\hline PfraucalD02_25_dT & P. fraudulenta, subfraudulenta, calliantha & $28 \mathrm{~S}$ \\
\hline PcaciD01_25_dT & P. caciantha & $28 \mathrm{~S}$ \\
\hline PcaciD02_25_dT & P. caciantha & $28 \mathrm{~S}$ \\
\hline PcaciD04_25_dT & P. caciantha & $28 \mathrm{~S}$ \\
\hline Pcal1D01_25_dT & P. calliantha & $28 \mathrm{~S}$ \\
\hline PmanD01_25_dT & P. manii & $28 \mathrm{~S}$ \\
\hline Pman2D02_25_dT & P. manii & $28 \mathrm{~S}$ \\
\hline Pman2D03_25_dT & P. manii & $28 \mathrm{~S}$ \\
\hline Pman2D05_25_dT & P. manii & $28 \mathrm{~S}$ \\
\hline Pdel4D01_25_dT & P. cf. delicatissima Clade4 & $28 \mathrm{~S}$ \\
\hline
\end{tabular}


Table 2. Cont.

\begin{tabular}{|c|c|c|}
\hline Pdel4D02_25_dT & P. cf. delicatissima Clade4 & $28 \mathrm{~S}$ \\
\hline Pdel3B_25_dT & P. delicatissima clade $3+$ micropora & $28 \mathrm{~S}$ \\
\hline Pdel3A_25_dT & P. delicatissima clade $3+$ micropora & $28 \mathrm{~S}$ \\
\hline CompPdel3_25_dT & Competitor Pdel3A & $28 \mathrm{~S}$ \\
\hline Pdel1D01_25_dT & P. delicatissima Clade1 & $28 \mathrm{~S}$ \\
\hline Pcaldel2D01_25_dT & P. delicatissima Clade2 & $28 \mathrm{~S}$ \\
\hline PcaldelD03_25_dT & P. delicatissima Clade2 and calliantha & $28 \mathrm{~S}$ \\
\hline Pdel4D03_25_dT & P. delicatissima Clade4 & $28 \mathrm{~S}$ \\
\hline PgalaD01_25_dT & P. galaxiae & $28 \mathrm{~S}$ \\
\hline PgalaD02_25_dT & P. galaxiae & $28 \mathrm{~S}$ \\
\hline PgalaD04_25_dT & P. galaxiae & $28 \mathrm{~S}$ \\
\hline PmultS01_25_dT & P. multiseries & $18 \mathrm{~S}$ \\
\hline PmultD02_25_dT & P. multiseries & $28 \mathrm{~S}$ \\
\hline PmultcalD01_25_dT & P. multiseries and calliantha & $28 \mathrm{~S}$ \\
\hline PmultcalD03_25_dT & P. multiseries and calliantha & $28 \mathrm{~S}$ \\
\hline PmultcalD04_25_dT & P. multiseries and calliantha & $28 \mathrm{~S}$ \\
\hline PcalfrauD04_25_dT & P. fraudulenta and multistriata & $28 \mathrm{~S}$ \\
\hline PmulaD03_25_dT & P. multistriata & $28 \mathrm{~S}$ \\
\hline PmulacalD02_25_dT & P. multistriata and calliantha & $28 \mathrm{~S}$ \\
\hline PpdeD01_25_dT & P. pseudodelicatissima and cuspidata & $28 \mathrm{~S}$ \\
\hline PpdeD02_25_dT & P. pseudodelicatissima and cuspidata & $28 \mathrm{~S}$ \\
\hline PpungcalS01_25_dT & P. pungens and calliantha & $18 \mathrm{~S}$ \\
\hline PpungcalD02_25_dT & P. pungens and calliantha & $28 \mathrm{~S}$ \\
\hline PpungcalD04_25_dT & P. pungens and calliantha & $28 \mathrm{~S}$ \\
\hline PsercalD01_25_dT & P. seriata and calliantha & $28 \mathrm{~S}$ \\
\hline CtoxS05_25_dT & cf. Chatonella sp. & $18 \mathrm{~S}$ \\
\hline CtoxiS07_25_dT & cf. Chatonella sp. & $18 \mathrm{~S}$ \\
\hline CtoxiS09_25_dT & cf. Chatonella sp. & $18 \mathrm{~S}$ \\
\hline PfarD01_25_dT & Pseudochattonella farcimen & $28 \mathrm{~S}$ \\
\hline PverD01_25_dT & Pseudochattonella verruculosa & $28 \mathrm{~S}$ \\
\hline SSHaka0193A25_dT & Heterosigma akashiwo & $18 \mathrm{~S}$ \\
\hline SSHaka0200A25_dT & H. akashiwo & $18 \mathrm{~S}$ \\
\hline LSHaka0544A25b_dT & H. akashiwo & $28 \mathrm{~S}$ \\
\hline LSHaka0268A25_dT & H. akashiwo & $28 \mathrm{~S}$ \\
\hline LSHaka0544A25c_dT & H. akashiwo & $28 \mathrm{~S}$ \\
\hline LSHaka0548A25_dT & H. akashiwo & $28 \mathrm{~S}$ \\
\hline LSHaka0329A25_dT & H. akashiwo & $28 \mathrm{~S}$ \\
\hline LSHaka0358A24_dT & H. akashiwo & $28 \mathrm{~S}$ \\
\hline
\end{tabular}

\subsection{Microarray Hybridization}

Before use, slides were blocked by incubating the DNA chips in a blocking solution (0.02\% SDS, $2 \times \mathrm{SSC}$ ) for $20 \mathrm{~min}$ at $50{ }^{\circ} \mathrm{C}$ and $\sim 70 \mathrm{rpm}$ in the dark. The slides were washed once in $\mathrm{ddH}_{2} \mathrm{O}$ for 10 min at $50{ }^{\circ} \mathrm{C}$ and twice always in fresh $\mathrm{ddH}_{2} \mathrm{O}$ for $15 \mathrm{~min}$ at $\mathrm{RT}$ and $\sim 70 \mathrm{rpm}$ in the dark. The slides were dried by centrifugation in a glass dish for $3 \mathrm{~min}$ at $900 \mathrm{rpm}$ and stored in the fridge (possible for up to two month). 
Labeled field samples ( $1 \mu \mathrm{g}$ RNA) were mixed with $30 \mu \mathrm{L}$ of $2 \times$ hybridization buffer, $3 \mu \mathrm{L}$ Poly-dA $(1 \mu \mathrm{M}), 10 \mathrm{ng}$ TBP-control and adjusted with nuclease-free water to $45 \mu \mathrm{L}$. Poly-dA is added to block the poly-T spacer on the probe and TBP is the TATA box gene fragment added as the positive hybridization control. The labeled RNA was then denatured for 5 min at $94{ }^{\circ} \mathrm{C}$. After denaturation, the samples were shortly placed on ice and $15 \mu \mathrm{L}$ of KREAblock (background blocker from KREATECH) was added. Slides were placed into an array holder; coverslips (LifterSlips, Erie Scientific, USA) were cleaned and placed onto the microarrays. Half of the hybridization mixture $(30 \mu \mathrm{L})$ was added to one microarray. Hybridization was carried out for $1 \mathrm{~h}$ at $65{ }^{\circ} \mathrm{C}$ in a $50 \mathrm{~mL}$ Falcon tube containing a wet Whatman paper. The DNA chips were washed three times and shaken $(\sim 70 \mathrm{rpm})$ in the dark under stringent conditions. The washings were always undertaken for $10 \mathrm{~min}$. The incubation in the first washing buffer $(2 \times \mathrm{SSC} / 10 \mathrm{mM}$ EDTA/0.05\% SDS) and the second washing buffer $(0.5 \times \mathrm{SSC} / 10 \mathrm{mM}$ EDTA) was done at room temperature. The incubation in the third washing buffer $(0.2 \times \mathrm{SSC} / 10 \mathrm{mM}$ EDTA) was done at $50^{\circ} \mathrm{C}$.

\subsection{Data Analysis}

Obtained fluorescent signals and the surrounding background intensity were calculated by superimposing a grid of circles (midtal_ver32_20110429.gal or MIDTAL_V3.3.gal) onto the scanned image using the GenePix 6.0 software. First results were processed through the phylochip analyzer program to generate a hierarchy file to establish the hierarchical levels of the probes on the chip [19]. The hierarchy file and hybridization results were then progressed with the GPR-Analyzer version 1.27 and the hierarchy file version 1.06 [20]. A signal-to-noise ratio ( $\mathrm{S} / \mathrm{N}$ ratio) above two was taken as a cutoff for a positive signal. To compare values from different hybridizations, signals were normalized using the internal control DunGS02_25_dT (corresponds to Dunaliella tertiolecta), and replicates averaged. The mean of the total signal intensity and its standard deviation (SD) for the replicates of each probe, which are depicted in the graphs below, can be found in supplementary S2. All microarray results were uploaded to the MIDTAL database at http://www.mba.ac.uk/midtal. Specific instructions can be found in the MIDTAL manual [14] to open a new account from this site.

\section{Results and Discussion}

\subsection{Species Composition during Sampling Period Based on Cell Counts}

The samples were characterized by a mixed assembly of species (Table S1) and dominated mainly by diatoms and cryptomonads (Table 3). Dominant taxa in the five samples were Chaetoceros spp., Cryptomonadales, Asterionellopsis glacialis and Cylindrotheca closterium. The last sample (6A) by the end of October showed also a bloom of Nitzschia spp. With respect to potentially toxic algae (Tables 4 and S1), it was possible to observe several developments of Pseudo-nitzschia species. Based on morphological characteristics of the valves and on previous distinctions made by other authors [21,22], species of Pseudo-nitzschia were grouped and counted using four identification groups: the "slender" (seriata complex, i.e., P. multiseries + pungens), the "thin" (valve $<3 \mu \mathrm{m}$, delicatissima complex, i.e., P. calliantha + delicatissima + pseudodelicatissima), the "wide" (valve $>3 \mu \mathrm{m}$, seriata complex, i.e., P. australis + fraudulenta + seriata + subpacifica), and the "sigmoid" (P. multistriata). 
The sigmoid group was observed with low abundances in August (sample 3A, 400 cells $\cdot \mathrm{L}^{-1}$ ) and higher abundances in October (samples 4A and 6A) with a maximum of 40,600 cells $\cdot \mathrm{L}^{-1}$ in the last sample. In July (sample 1A), it was possible to observe a high concentration of the "wide" Pseudo-nitzschia (P. australis, fraudulenta, seriata, and subpacifica) with 30,200 cells $\cdot \mathrm{L}^{-1}$, as well as 2 cells of Alexandrium spp.. At the beginning of August (sample 2A) and the beginning of October (sample 4A), species of Prorocentrum (P. cf. minimum, balticum, and cordatum) were detected with 400 cells $\cdot \mathrm{L}^{-1}$. Furthermore, 7,000 cells $\cdot \mathrm{L}^{-1}$ of Pseudo-nitzschia (mainly from the "thin" group) were observed in sample 2A. Except for the aforementioned Pseudo-nitzschia multistriata (400 cells $\cdot \mathrm{L}^{-1}$ ), no potentially toxic species were observed at the end of August (sample 3A). In both October samples (4A and 6A), it was possible to identify Heterosigma akashiwo with 600 and 400 cells $\cdot \mathrm{L}^{-1}$, respectively. In the late October sample (6A), 30 cells $\cdot \mathrm{L}^{-1}$ of Dinophysis caudata were also counted.

Despite few events of potentially toxic algae blooms during our study period, we can point out the presence of five genera in our samples (Pseudo-nitzschia, Heterosigma, Prorocentrum, Alexandrium, and Dinophysis) that are all represented by probes on the MIDTAL microarray.

Table 3. Non-toxic cells in high abundance at the Arcachon site over the sampling period in cells $\cdot \mathrm{L}^{-1}$.

\begin{tabular}{cccccc}
\hline Species & $\mathbf{1 A}$ & $\mathbf{2 A}$ & $\mathbf{3 A}$ & $\mathbf{4 A}$ & $\mathbf{6 A}$ \\
\hline Cryptomonadales & 50.700 & 331.500 & 181.400 & 194.100 & 36.400 \\
Chaetoceros spp. & 59.000 & 1.841 .200 & 629.100 & 4.400 & 40.600 \\
Asterionellopsis glacialis & 19.000 & 32.400 & 0 & 27.800 & 446.400 \\
Nitzschia spp. & 1.200 & 400 & 600 & 11.000 & 73.200 \\
\hline
\end{tabular}

Table 4. Cell counts of potentially harmful cells at the Arcachon site over the sampling period.

\begin{tabular}{cccccc}
\hline Species & $\mathbf{1 A}$ & $\mathbf{2 A}$ & $\mathbf{3 A}$ & $\mathbf{4 A}$ & $\mathbf{6 A}$ \\
\hline Pseudo-nitzschia spp. & 30,200 & 7,000 & 0 & 0 & 800 \\
Pseudo-nitzschia multistriata & 0 & 0 & 400 & 1,700 & 40,600 \\
Prorocentrum minimum, & 0 & 400 & 0 & 400 & 0 \\
balticum, cordatum & & & & & \\
Heterosigma akashiwo & 0 & 0 & 0 & 600 & 400 \\
Alexandrium spp. & 20 & 0 & 0 & 0 & 0 \\
Dinophysis caudata & 0 & 0 & 0 & 0 & 30 \\
\hline
\end{tabular}

\subsection{Relations between Microarray Signal, Cell Counts and Detection of Toxins}

The insertion of a taxonomic hierarchy file in the GPR-Analyzer [20] gave us the advantage to distinguish false positives among the species-specific probes in the microarray analysis and exclude them prior to data interpretation. Briefly, for a species to be present, the entire taxonomic hierarchy leading to that species must also be present. The slopes of culture calibration curves of each species incorporated into the GPR-Analyzer allow for the transformation of microarray signals into cell abundances.

\subsubsection{Pseudo-nitzschia and ASP Toxins}

Pseudo-nitzschia was observed throughout the sampling period and is the only potentially toxic phytoplankton genus that formed a dominant bloom according to the cell counts. The microarray 
detected three of five Pseudo-nitzschia genus-level probes (PSN + some Frags_25_dT, PSN + FRAGS02-25new_dT and PsnGS02_25_dT) throughout the sampling period (Figure 3(a)). The other two generic-level probes (PsnGS01_25_dT, and PSN no pungens_25_dT) were excluded because the $\mathrm{S} / \mathrm{N}$ ratio was not always above two. These two are not as strong as the other three probes, which are positioned at the top of the hierarchy file and thus do not cause the hierarchy test to fail. Weaker probes are always placed inside stronger probes to prevent such failure of true positives. Domoic acid (DA) was detected with ELISA [23] (Table 5) in both October samples (4A and 6A) but not in sample 3A (22.08.2011) where 400 cells $\cdot \mathrm{L}^{-1}$ of $P$. multistriata were counted. This result suggests that the threshold for detecting DA with ELISA is somewhere between 400 and 1,700 cells $\cdot \mathrm{L}^{-1}$ for the species $P$. multistriata. Furthermore, the Multi SPR gave no signal even though the last October sample had 40,600 cells $\cdot \mathrm{L}^{-1}$. In general, it was found that the ELISA was more sensitive to lower amounts of toxin than the Multi SPR [23]. Because it is quite arduous to identify Pseudo-nitzschia multistriata to the species-level with light microscopy, and because some of our species-specific probes are still being optimized, we focused our comparison on P. multistriata (i.e., the "sigmoid" group) with two genus-level probes and three species-level probes on the array. The October bloom of 40,600 cells. $\mathrm{L}^{-1}$ of Pseudo-nitzschia multistriata matched the microarray with positive hits ( $\mathrm{S} / \mathrm{N}$ ratio above 2 ) of the two genus-level probes (PSN + some Frags_25_dT and PSN+FRAGS02-25new_dT) and the three species-level probes (PmulausD01_25_dT, PmulacalD02_25_dT, and PmulaD03_25_dT) (Figure 3(b)). The probe PcalfrauD04_25_dT (now interpreted to be a genus-level probe because it cross-reacted with all Pseudo-nitzschia spp. tested) showed consistent high signals for all Pseudo-nitzschia spp. in calibration curves (data not shown) and field samples.

Figure 3. Microarray signals of (a) the Pseudo-nitzschia spp. Genus-level probes (PSN + some Frags_25_dT, PSN + FRAGS02-new_dT and PsnGS02_25_dT) and (b) P. multistriata species-level probes (PmulausD01_25_dT, PmulacalD02_25_dT, PmulaD03_25_dT) normalized against Dunaliella tertiolecta (DunGS02_25_dT) for the field samples taken in Arcachon Bay, France and compared to cell counts. The graphs show only probes that yielded a signal above the detection limit (signal/noise ratio > 2), except for PmulaD03_25_dT, which is only in sample 6A above the $\mathrm{S} / \mathrm{N}$ ratio. The sampling dates $(24.07 .2011,08.08 .2011$, 22.08.2011, 04.10.201 and 20.10.2011) correspond to the sampling names: 1A, 2A, 3A, 4A and 6A. Cell counts are depicted in $\log 10$ on the secondary y-axis and as columns.
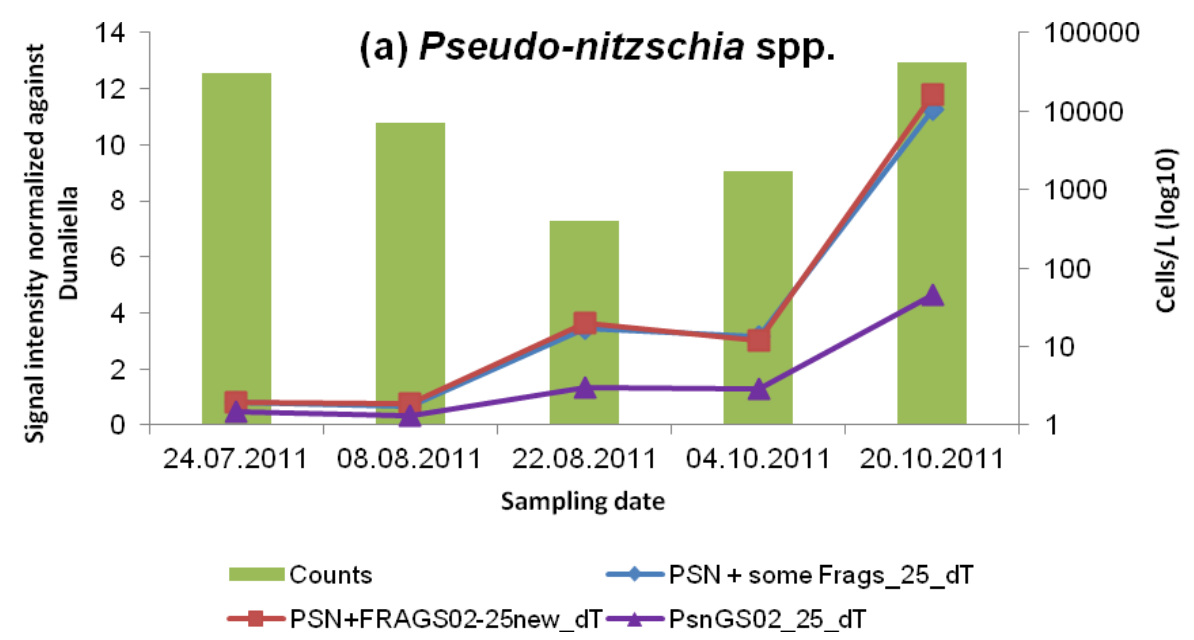
Figure 3. Cont.

(b) Pseudo-nitzschia multistriata

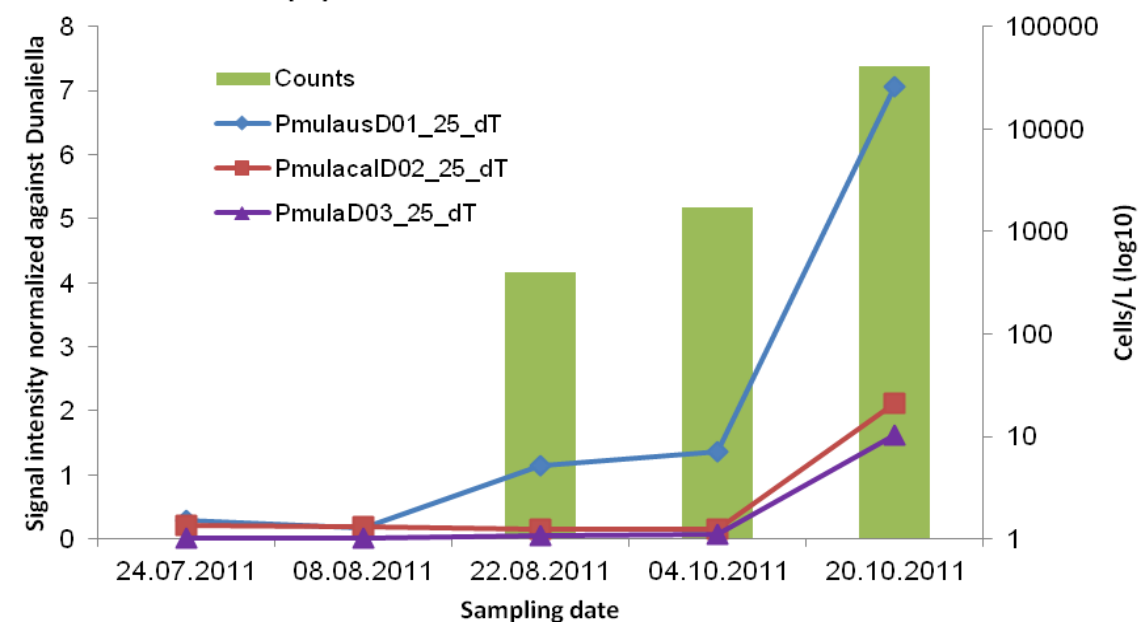

Table 5. Toxins measured by Multi SPR and ELISA during the sampling period in Arcachon Bay, France, adapted from [23].

\begin{tabular}{|c|c|c|c|c|c|c|}
\hline \multirow[b]{2}{*}{ Sampling Date } & \multicolumn{2}{|c|}{$\begin{array}{l}\text { STX } \\
\text { (PSP) }\end{array}$} & \multicolumn{2}{|c|}{$\begin{array}{c}\text { Okadaic Acid, DTXS } \\
\text { (DSP) }\end{array}$} & \multicolumn{2}{|c|}{$\begin{array}{c}\text { Domoic Acid } \\
\text { (ASP) }\end{array}$} \\
\hline & Multi SPR & ELISA & Multi SPR & ELISA & Multi SPR & ELISA \\
\hline 24.07.2011 & - & - & - & - & - & - \\
\hline 08.08 .2011 & - & - & - & + & - & - \\
\hline 22.08 .2011 & - & + & - & + & - & - \\
\hline 04.10 .2011 & - & + & - & + & - & + \\
\hline 20.10 .2011 & + & + & - & + & - & + \\
\hline
\end{tabular}

\subsubsection{Dinophysis and Prorocentrum and DSP Toxins}

The non-toxic species Dinophysis tripos was counted in sample $1 \mathrm{~A}$ ( 20 cells $\cdot \mathrm{L}^{-1}$ ) and the toxic species $D$. caudata in sample 6A (30 cells $\cdot \mathrm{L}^{-1}$, Table 4$)$. No other Dinophysis species was identified by using light microscopy. Only the top genus-level probe in the hierarchy for Dinophysis (DphyGS03_25_dT) was detected with the microarray in sample 6A, but no species-specific probes were detected with the microarray in sample 6A. This result suggests that the microarray threshold for D. caudata species probe is above 30 cells.

Cells from the potentially toxic genus Prorocentrum (group of $P$. minimum, balticum, and cordatum) were counted in samples $2 \mathrm{~A}$ and $4 \mathrm{~A}$ (both with 400 cells $\cdot \mathrm{L}^{-1}$, Table 4). In addition, two planktonic usually considered harmless species, P. micans (sample 2A) and P. triestinum (sample 3A, 4A and 6A), were also identified by light microscopy with abundances $\leq 800$ cells $\cdot \mathrm{L}^{-1}$ (Table S1). No Prorocentrum species were counted in sample 1A. None of the planktonic clade-level probe for Prorocentrum ProroFBS02_25_dT and the species-specific probes for P. minimum (PminiD01_25_dT) and P. micans (PmicaD02_25_dT) of the microarray detected the presence of these taxa. It is likely that they require higher cell numbers to achieve a signal. With the third generation of the MIDTAL microarray new probes for Prorocentrum (two clade-level and six species-level probes) were tested, but without the poly dT_15 spacer region to raise the probes higher above the surface because they 
were still under testing for specificity. The new planktonic Prorocentrum probe ProroFPS01 was detected in samples 1A, 2A and 6A whereas the benthic Prorocentrum probe ProroFBS01 was detected in samples 4A and 6A (Figure 4(a)). New species-specific probes were made for the benthic species $P$. belizeanum, maculosum, rathymum and mexicanum. The probe PbeliS01 specific for $P$. belizeanum was detected with the microarray in samples $4 \mathrm{~A}$ and $6 \mathrm{~A}$ and the probe PrathD01 specific for P. rathymum and mexicanum was detected in sample 6A (Figure 4(a)). As for both samples, the higher probe ProroFBS01 (benthic Prorocentrum) was detected; the species-specific probes are not false positives and point out the limitation of microscopic cell counting. The specificity of theses Prorocentrum species has only been tested against a limited number of species and it is also likely that these probes are cross-reacting to another species present in the sample. $P$. rathymum is found in Malaysia and in the Mediterranean and $P$. mexicanum has a Caribbean distribution. More work is needed to clarify the taxon that is reacting with this probe. One way to achieve this is to use the probe as a FISH probe and sort the labeled cells or look at them in the microscope.

Okadaic acid was detected by ELISA in all samples except for the first (sample 1A), and the Multi SPR gave no signal at all. We presume that because Prorocentrum was more abundant than Dinophysis; its species is the source of this toxin.

Figure 4. (a) Normalized signal of Prorocentrum-level probes (ProroFPS01 and ProroFBS01) and the species-level probes PrathD01 and PbeliS01. (b) Normalized signal of the Alexandrium genus-level probe AlexGD01_25_dT.

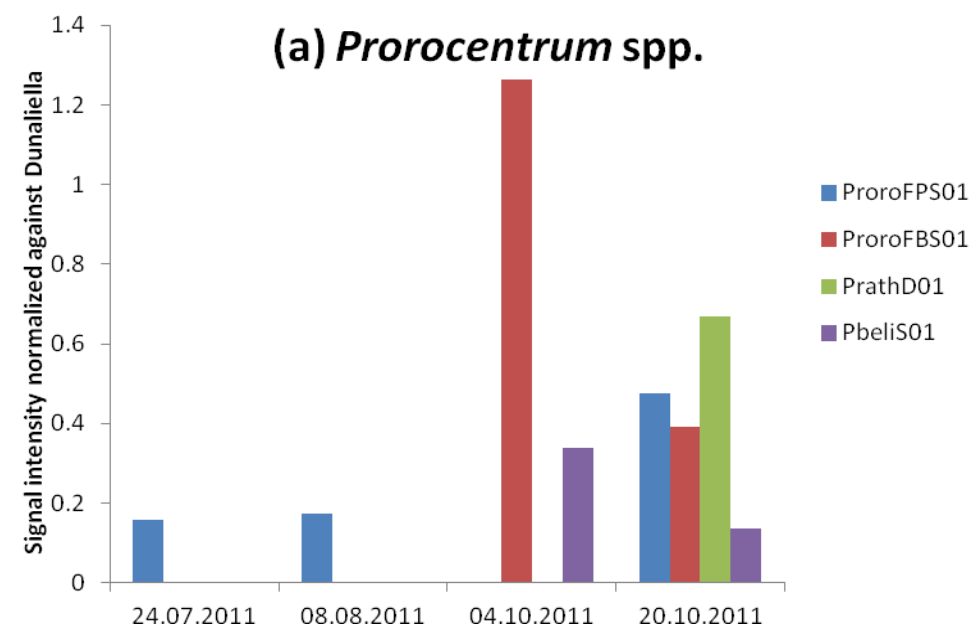

(b) Alexandrium spp.

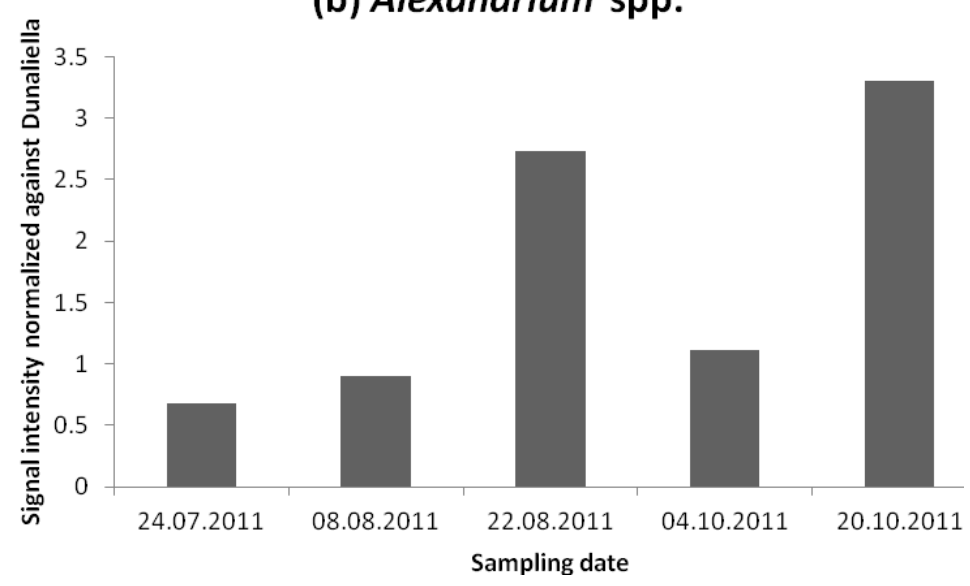




\subsubsection{Alexandrium and PSP Toxins}

Two cells of the genus Alexandrium ( $c a .20$ cells $\cdot \mathrm{L}^{-1}$ ) were counted only in sample $1 \mathrm{~A}$, whereas the microarray detected it throughout the sampling period (Figure 4(b)) with the highest signal at the end of October (sample 6A). Furthermore, PSP toxins were detected with ELISA in late August (sample 3A) and the remaining sampling period, as well as with the Multi SPR in sample 6A (Table 5, see [23] for more discussion on toxin found in these samples). If toxin probes are efficient and therefore PSP toxins are indeed present, there are two different ways to explain the absence of Alexandrium in cell counts: either Alexandrium cells have effectively been missed with the microscope, or there are other PSP-containing microorganisms in the water that are not identified. Neither A. ostenfeldii, A. minutum nor $A$. tamarense probes were detected by the microarray and their calibration curves for each specific probe have a detection limit of 200 cells [24]. Thus, we are unsure as to which species could be contributing to the PSP toxin profile. It could be Gymnodinium catenatum (see below) or another member of the genus Alexandrium. A. pseudogonyaulax could be a potentially missed Alexandrium species. There are no A. pseudogonyaulax-specific probes on the microarray. There are also many species that are not well investigated for toxin production. However, our data underlines the importance of including additional genus- and species-level probes for Alexandrium, in order to capture the full variability found in this genus. In any case, the detection of Alexandrium and its PSP toxins shows the advantage of the combination of the two methods (species and toxins) to detect harmful species, as well as to detect new invasive species as climate changes and tropical species move into temperate regions.

\subsubsection{Heterosigma akashiwo}

The heterokont Heterosigma akashiwo was identified by microscopic cell counts in sample 4A (600 cells $\cdot \mathrm{L}^{-1}$ ) and $6 \mathrm{~A}\left(400\right.$ cells $\left.\cdot \mathrm{L}^{-1}\right)$. The microarray detected this taxon with the species-specific probe LSHaka054425b_dT in all samples except 3A. In addition, two more species-specific probes gave positive signals in sample 4A (LSHaka0268A25_dT and LSHaka0358A24_dT), and four in sample 6A (LSHaka0268A25_dT, LSHaka0544A25c_dT, LSHaka0329A25_dT, and SSHaka0200A25_dT). This species can be difficult to identify, especially once preserved in Lugol's. Two species-specific probes were designed from the $18 \mathrm{~S}$ region (SSHaka) and six more from the $28 \mathrm{~S}$ region (LSHaka) for H. akashiwo (Table 2, [25]). Their calibration curves show the sensitivity of each probe and point out a low affinity with the $H$. akashiwo RNA. Some probes showed no sensitivity below 5 or even 25 ng of RNA, i.e., more than 700 cells are required to get a $\mathrm{S} / \mathrm{N}$ ratio above two. This means that, in our case, we had around 230 cells $\cdot \mathrm{L}^{-1}$ of $H$. akashiwo because not all probes were detected.

\subsubsection{Species Unfound by Cell Counts but Identified with Microarray and Hierarchy File}

\section{Fish Killing Species}

Lugol's-fixed cells of Pseudochattonella are difficult to identify by light microscopy because the cell shape changes and the discharge of mucocysts gives them a warty appearance [26]. It is possible to distinguish the two sister species $P$. farcimen and $P$. verruculosa molecularly, because the two differ 
in several bases in the large ribosomal subunit [26]. In sample 6A, all genus-level probes of Pseudochattonella (PschGS01_25_dT, PschGS04_25_dT, PschGS05_25_dT) and the two species-level probes PfarD01_25_dT (P. farcimen) and PverD01_25_dT (P. verruculosa) were detected with a signal-to-noise above 2 (Figure 5(a)). The integrated calculation of cells $\mathrm{L}^{-1}$ in the GPR-Analyzer [20] revealed for Pseudochattonella farcimen 19,463 cells $\cdot \mathrm{L}^{-1}$ and for Pseudochattonella verruculosa 48,428 cells $\cdot \mathrm{L}^{-1}$, which is likely to be overestimated. Indeed, this species has only been identified in fjords and open waters of the North Sea, Skagerrak, and Kattegat, whose temperatures are below $10{ }^{\circ} \mathrm{C}$ [27]. During the summer-fall season, waters in Arcachon Bay are typically $>25{ }^{\circ} \mathrm{C}$ [28]. Our results suggest perhaps another very closely related species as yet undetected could be in Arcachon Bay if the distribution of this species is exclusively in cold temperate waters. If this probe continues to show positive results, the probe could be used as a FISH probe to retrieve the cells giving the signal on the microarray for further investigations. Cells hybridized by the probe could be sorted by flow cytometry and investigated morphologically or molecularly. Once identified, the cells could later be brought into culture and their toxicity tested with bioassays.

Figure 5. (a) Normalized signal intensity of the genus-level probes (PschGS01_25_dT, PschGS04_25_dT, PschGS05_25_dT) of Pseudochattonella and the two species-level probes PfarD01_25_dT (Pseudochattonella farcimen) and PverD01_25_dT (Pseudochattonella verruculosa) for sample 6A (20.10.2011) only. (b) Normalized signal intensity of the class-level probes (PrymS03_25_dT, PrymS01_25_dT) and the clade-level probe (Clade01old_25_dT) of Prymnesium spp. (c) Normalized signal intensity of the genus-level probe of Karlodinium spp. (KargeD01_25_Dt).

\section{(a) Pseudochattonella spp., sample 6A}
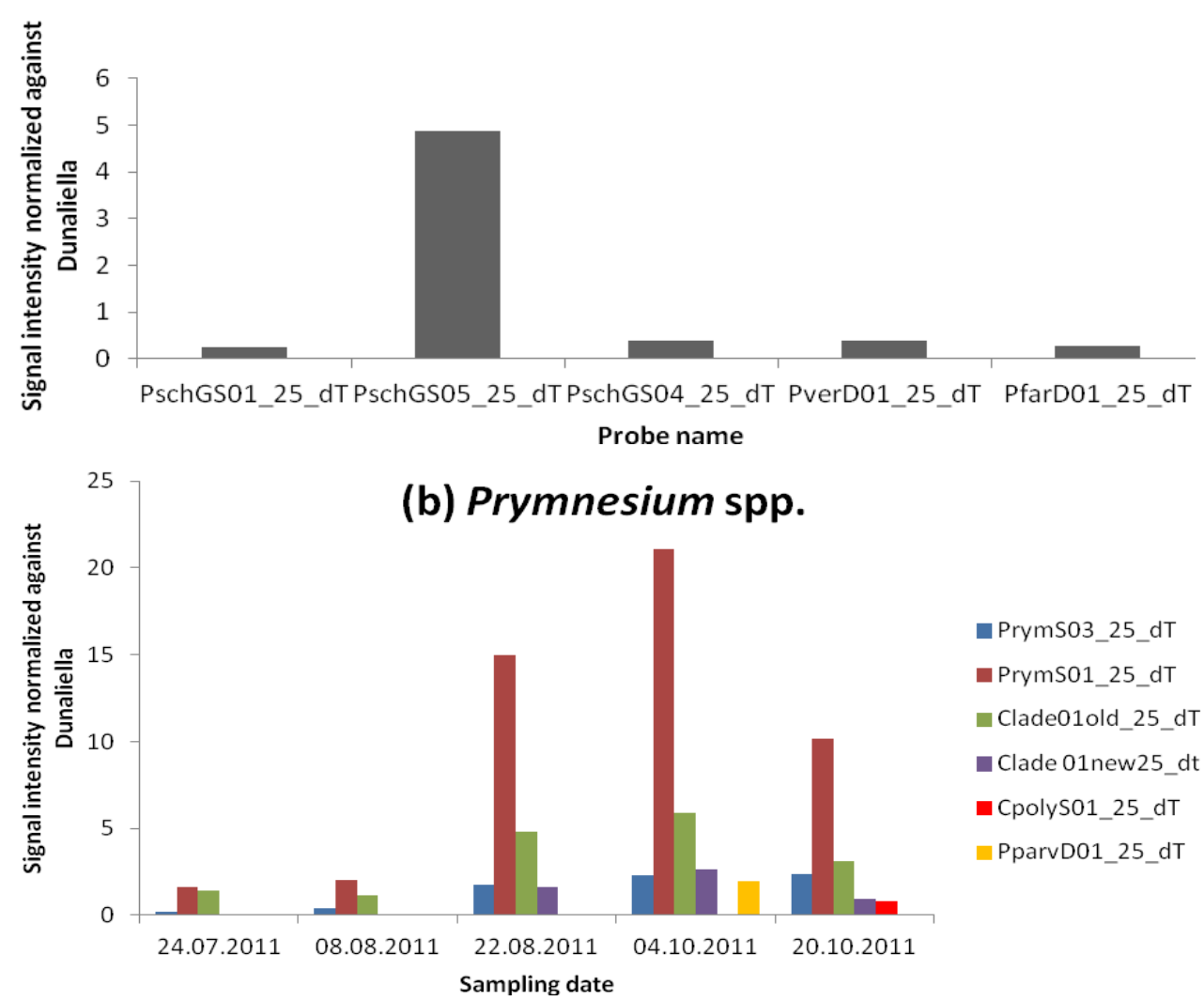
Figure 5. Cont.

(c) Karlodinium spp.

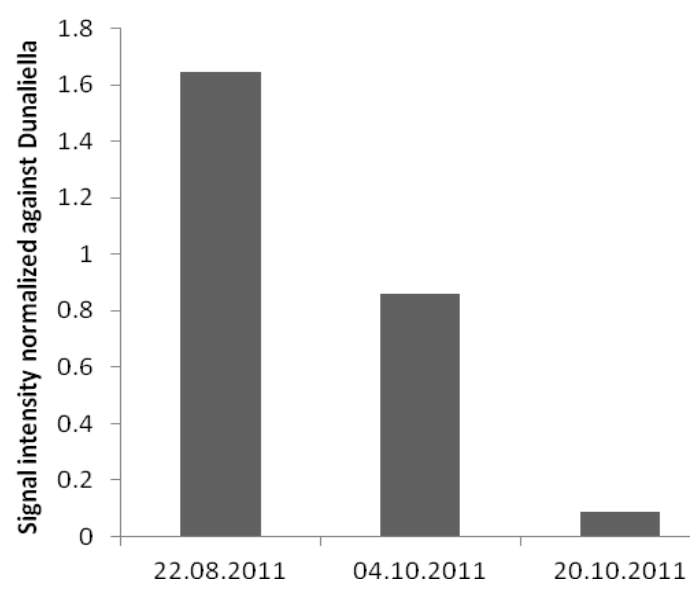

No Prymnesiophyta were identified by cell counts, but the higher group probe for Prymnesiophyta (PrymS01_25_dT), the class level for Prymnesiophyceae (PrymS03_25_dT) and the clade-level probe for Prymnesium clade B1 (Clade01old_25_dT) were detected throughout the sampling period (Figure 5(b)). The second clade-level probe for Prymnesium clade B1 (Clade01new25_dT) was detected in samples 3A, 4A and 6A. Furthermore, the species-level probe for P. polylepis (CpolyS01_25_dT) was detected in sample 6A and in sample 4A the species-level probe for P. parvum (PparvD01_25_dT). This indicates the potential for a fish-killing event in Arcachon Bay under the appropriate conditions for growth. Although the Prymnesiophyta group is taken into account within the harmful phytoplankton monitoring program, the small size of this genus $(<10 \mu \mathrm{m})$ as well as the smaller volume of water used for Utermöhl sedimentation and observation (100 $\mathrm{mL}$ maximum) than the volume of filtered seawater for RNA extraction, avoid any faithful microscopy identification and counting. The microarray can detect Prymnesium above $5 \mathrm{ng}$, which is equivalent to 3,800 cells for P. polylepis and 8,800 cells for $P$. parvum [29]. In our case (3 L filtered) it means 1,100 and 2,500 cells $\cdot \mathrm{L}^{-1}$, respectively, which are high enough to be counted in a $10-$ or $100-\mathrm{mL}$ sedimented subsample.

The genus Karlodinium (KargeD01_25_dT) was first detected in sample 3A and then with decreasing signals onwards (Figure 5(c)). Karlodinium veneficum is a high-biomass producer and the collapse of a bloom leads to the production of a surface scum that is visible as an oily, brownish discoloration of the water and kills fish and other gill-breathing animals [30]. However, no signals were detected for the six species-specific probes of $K$. veneficum present on the microarray. Based on their calibration curves (data not shown), the detection limit for four of the six probes is around 247 cells. The species-specific level probes are more sensitive than the genus-level probe. Therefore, we can exclude this species as a potential candidate being present in the bay. This is another example of how the microarray can detect potentially toxic species that are not counted or identified as being potentially toxic.

\section{Azaspiracid Shellfish Poisoning (AZP) Toxins Producer}

Azadinium spp. (AzaGS01_25_dT) was detected in sample 4A but only in two out of five spots on two different microarray slides. This may not be a genuine signal, but this species has only recently 
described [31] and it is also a relatively arduous species to identify based on light microscopy. Not all monitoring agencies are able to adjust their cell counts routinely to account for this toxic species. At least three more toxic species have been recently isolated and described [32-34].

\section{Other PSP Toxins}

One species-level probe out of four for Gymnodinium catenatum (LSGcat0270A24_dT) was detected in samples 1A, 4A and 6A. In samples 4A and 6A, the microarray also detected another species-level probe for G. catenatum (SSGcat0826A27_dT). The signals were not very high (S/N ratio between 2.2 and 4.9). G. catenatum is known to cause PSP and could therefore contribute, besides Alexandrium, to its detection via the ELISA and Multi SPR.

\section{Conclusions}

The third generation of the MIDTAL microarray with its improved protocols has great potential to be used as a monitoring tool for toxic algae, even in non-bloom situations, although improvements and tests are still needed. The probes on the MIDTAL microarray have been designed from a global database and the specificity tests done on the probes were made from global isolates. Thus, the MIDTAL microarray can be regarded as a universal microarray that can be used globally. Its specificity has been tested at eight sites across Europe within the MIDTAL project over a two-year period and in no case did it fail to detect the presence of a toxic species when cross-validated with the toxin array. Our results show the advantage of combining the MIDTAL microarray with toxin detection, especially for detecting species either not counted in the cell counts because of low volume or poor preservation, or because they are new to the area, i.e., invasive species, such as new toxin-producing species (Azadinium and the causative species producing the signal for PSP) that might be new to the area or not yet routinely counted in any monitoring program. We also found several species with the microarray that were difficult to identify using light microscopy, such as Prymnesium parvum, Pseudochattonella, and Azadinium. A more specific identification requires electron microscopy. In other cases, such as the recording of Karlodinium, it is likely that the volume difference between the species filtered and settled for counting reflects the potential of the microarray to be more sensitive for the detection of rare events.

\section{Acknowledgments}

YDA thanks her crew members (Laurent Letort and Francis Prince) for sampling in Arcachon Bay. Cell counts were supplied by Nadine Masson Neaud and Danièle Maurer from IFREMER/LER Arcachon (Ifremer/Quadrige $2 /$ Rephy DATA). This work was funded by the EU's 7th Framework Program (FP7-ENV-2007-MIDTAL-201724).

\section{References}

1. Hallegraeff, G.M. Harmful algal blooms: A global overview. In Manual on Harmful Marine Microalgae; IOC-UNESCO: Paris, France, 2003; Volume 11, pp. 25-49. 
2. Moestrup, Ø.; Akselman, R.; Cronberg, G.; Elbraechter, M.; Fraga, S.; Halim, Y.; Hansen, G.; Hoppenrath, M.; Larsen, J.; Lundholm, N.; Nguyen, L.N.; Zingone, A. IOC-UNESCO Taxonomic Reference List of Harmful Micro Algae. Available online at http://www.marinespecies.org/HAB (accessed on 24 December 2012).

3. Yasumoto, T.; Murata, M.; Oshima, Y.; Sano, M.; Matsumoto, G.K.; Clardy, J. Diarrhetic shellfish toxins. Tetrahedron 1985, 41, 1019-1025.

4. Cotterill, F.P.D. Systematics, biological knowledge and environmental conservation. Biodivers. Conserv. 1995, 4, 183-205.

5. Gómez, F. Phytoplankton invasions: Comments on the validity of categorizing the non-indigenous dinoflagellates and diatoms in European seas. Mar. Pollut. Bull. 2008, 56, 620-628.

6. DeSantis, T.Z.; Stone, C.E.; Murray, S.R.; Moberg, J.P.; Andersen, G.L. Rapid quantification and taxonomic classification of environmental DNA from both prokaryotic and eukaryotic origins using a microarray. FEMS Microbiol. Lett. 2005, 245, 271-278.

7. DeSantis, T.Z.; Brodie, E.L.; Moberg, J.P.; Zubieta, I.X.; Piceno, Y.M.; Andersen, G.L. High-density universal $16 \mathrm{~S}$ rRNA microarray analysis reveals broader diversity than typical clone library when sampling the environment. Microbial Ecol. 2007, 53, 371-383.

8. Yergeau, E.; Arbour, M.; Brousseau, R.; Juck, D.; Lawrence, J.R.; Masson, L.; Whyte, L.G.; Greer, C.W. Microarray and real-time PCR analyses of the responses of high-arctic soil bacteria to hydrocarbon pollution and bioremediation treatments. Appl. Environ. Microbiol. 2009, 75, 6258-6267.

9. Gescher, C.; Metfies, K.; Medlin, L.K. The ALEX CHIP-Development of a DNA chip for identification and monitoring of Alexandrium. Harmful Algae 2008, 7, 485-494.

10. Brodie, E.L.; DeSantis, T.Z.; Joyner, D.C.; Baek, S.M.; Larsen, J.T.; Andersen, G.L.; Hazen, T.C.; Richardson, P.M.; Herman, D.J.; Tokunaga, T.K.; Wan, J.M.; Firestone, M.K. Application of a high-density oligonucleotide microarray approach to study bacterial population dynamics during uranium reduction and reoxidation. Appl. Environ. Microbiol. 2006, 72, 6288-6298.

11. Brodie, E.L.; DeSantis, T.Z.; Parker, J.P. M.; Zubietta, I.X.; Piceno, Y.M.; Andersen, G.L. Urban aerosols harbor diverse and dynamic bacterial populations. PNAS 2007, 104, 299-304.

12. Delehanty, J.B.; Ligler, F.S. A microarray immunoassay for simultaneous detection of proteins and bacteria. Anal. Chem. 2002, 74, 5681-5687.

13. Lee, D.-Y.; Seto, P.; Korczak, R. DNA microarray-based detection and identification of waterborne protozoan pathogens. J. Microbiol. Meth. 2010, 80, 129-133.

14. Lewis, J.; Medlin, L.K.; Raine, R. MIDTAL (Microarrays for the Detection of Toxic Algae): A Protocol for a Successful Microarray Hybridisation and Analysis, 1st ed.; Gantner Verlag: Liechtenstein, Germany, 2012.

15. Medlin, L.K.; Schmidt, K. Molecular probes improve the taxonomic resolution of cryptophyte abundance in Arcachon Bay. Vie et Milieu 2010, 60, 9-15.

16. Kegel, J.U.; Del Amo, Y.; Medlin, L.K. Introduction to project MIDTAL: Its methods and samples from Arcachon Bay, France. Environ. Sci. Pollut. Res. 2012, doi: 10.1007/s11356-012-1299-9.

17. Campbell, K.; McGrath, T.; Sjölander, S.; Hanson, T.; Tidare, M.; Jansson, O.; Moberg, A.; Mooney, M.; Elliott, C.; Buijs, J. Use of a novel micro-fluidic device to create arrays for multiplex analysis of large and small molecular weight compounds by surface plasmon resonance.

Biosens. Bioelectron. 2011, 26, 3029-3036. 
18. Ludwig, W.; Strunk, O.; Westram, R.; Richter, L.; Meier, H.; Yadhukumar, H.; Buchner, A.; Lai, T.; Steppi, S.; Jobb, G.; et al. ARB: A software environment for sequence data. Nucl. Acid. Res. 2004, 32, 1363-1371.

19. Metfies, K.; Borsutzki, P.; Gescher, C.; Medlin, L.K.; Frickenhaus, S. PhylochipanalyserA program for analysing hierarchical probe sets. Mol. Ecol. Resour. 2008, 8, 99-102.

20. Dittami, S.M.; Edvardsen, B. GPR-Analyzer: A simple tool for quantitative analysis of hierarchical multispecies microarrays. Environ. Sci. Pollut. Res. 2012, doi: 10.1007/s11356-012-1051-5.

21. Hasle, G.R. Nitzschia and Fragilariopsis Species Studied in the Light and Electron Microscopes. II. The Group Pseudonitzschia; Universitetsforlaget: Oslo, Norway, 1965.

22. Hasle, G.R.; Syvertsen, E.E. Marine diatoms. In Identifying Marine Phytoplankton; Academic Press: San Diego, CA, USA, 1997; pp. 5-385.

23. McNamee, S.; Elliott, C.; Delahaut, P.; Campbell, K. Multiplex biotoxin surface plasmon resonance method for marine biotoxins in algal and seawater samples. Environ. Sci. Pollut. Res. 2012, doi: 10.1007/s11356-012-1329-7.

24. Taylor, J.; Kegel, J.U.; Lewis, J.; Medlin, L.K. Validation of the detection of Alexandrium spp using specific RNA probes tested in a microarray format: Calibration of signal based on variability of RNA content with environmental conditions. Harmful Algae 2013, submitted.

25. Blanco, E.P.; Hagström, J.; Salomon, P.S.; Graneli, E. Detection of Heterosigma akashiwo (Hada) using specific RNA probes: Variability of RNA content with environmental conditions. Harmful Algae 2013, submitted.

26. Dittami, S.M.; Hostyeva, V.; Egge, E.S.; Kegel, J.U.; Eikrem, W.; Edvardsen, B. Seasonal dynamics of harmful algae in outer Oslofjorden monitored by microarray, qPCR, and microscopy. Environ. Sci. Pollut. Res. 2013, doi: 10.1007/s11356-012-1392-0.

27. Naustvoll, L.-J. NOBANIS-Invasive Alien Species Fact Sheet Pseudochattonella farcimenFrom: Online Database of the North Eurpean and Baltic Network on Invasive Alien SpeciesNOBANIS. Available online: http://www.nobanis.org (accessed on 24 December 2012).

28. Glé, C.; Del Amo, Y.; Sautour, B.; Laborde, P.; Chardy, P. Variability of nutrients and phytoplankton primary production in a shallow macrotidal coastal ecosystem (Arcachon Bay, France). Estuar. Coast. Shelf Sci. 2008, 76, 642-656.

29. McCoy, G.R.; Touzet, N.; Fleming, G.T.; Raine, R. An evaluation of the applicability of microarrays for monitoring toxic algae in Irish coastal waters. Environ. Sci. Pollut. Res. 2012, doi: 10.1007/s11356-012-1294-1.

30. Swan River Trust Karlodinium Micrum Algal Bloom, March 2005. Fact Sheet. Available online: http://www.wa.canoe.org.au/?Page=7808 (accessed on 24 December 2012).

31. Tillmann, U.; Elbrächter, M.; Krock, B.; John, U.; Cembella, A. Azadinium spinosum gen. et sp. nov. (Dinophyceae) identified as a primary producer of azaspiracid toxins. Eur. J. Phycol. 2009, 44, 63-79.

32. Tillmann, U.; Elbrächter, M.; John, U.; Krock, B.; Cembella, A. Azadinium obesum (Dinophyceae), a new nontoxic species in the genus that can produce azaspiracid toxins. Phycologia 2010, 49, 169-182.

33. Tillmann, U.; Elbrächter, M.; John, U.; Krock, B. A new non-toxic species in the dinoflagellate genus Azadinium: A. poporum sp. nov. Eur. J. Phycol. 2011, 46, 74-87. 
34. Tillmann, U.; Salas, R.; Gottschling, M.; Krock, B.; O’Driscoll, D.; Elbrächter, M. Amphidoma languida sp. nov. (Dinophyceae) reveals a close relationship between Amphidoma and Azadinium. Protist 2012, 163, 701-719.

\section{Appendix}

Table S1. Cell densities (cell. $\mathrm{L}^{-1}$ ) of field samples taken at Arcachon Bay in France between July and October $2011(1 \mathrm{~A}=26.07,2 \mathrm{~A}=09.08,3 \mathrm{~A}=23.08 ; 4 \mathrm{~A}=06.10 ; 6 \mathrm{~A}=20.10)$ and identified by light microscopy. The identified genera and species are ordered into higher taxon groups. Toxic species are indicated with an *.

\begin{tabular}{|c|c|c|c|c|c|}
\hline Dinoflagellates & 1A & $2 \mathrm{~A}$ & 3A & 4A & $6 \mathrm{~A}$ \\
\hline * Alexandrium & 20 & 0 & 0 & 0 & 0 \\
\hline * Dinophysis caudata & 0 & 0 & 0 & 0 & 30 \\
\hline Dinophysis tripos & 20 & 0 & 0 & 0 & 0 \\
\hline Gymnodiniaceae & 0 & 400 & & 3,800 & 1,800 \\
\hline Katodinium & 100 & 0 & 0 & 0 & 0 \\
\hline Gyrodinium & 0 & 100 & 100 & 200 & 200 \\
\hline Gyrodinium spirale & 0 & 200 & 0 & 100 & 0 \\
\hline Prorocentrum micans & 0 & 100 & 0 & 0 & 0 \\
\hline * Prorocentrum minimum + balticum + cordatum & 0 & 400 & 0 & 400 & 0 \\
\hline Prorocentrum triestinum & 0 & 0 & 200 & 800 & 400 \\
\hline Protoperidinium & 0 & 200 & 0 & 800 & 600 \\
\hline Protoperidinium bipes & 0 & 400 & 5,400 & 600 & 0 \\
\hline Protoperidinium steinii + pyriforme & 0 & 0 & 100 & 0 & 0 \\
\hline Protoperidinium diabolus & 0 & 0 & 200 & 0 & 0 \\
\hline Heterocapsa niei & 0 & 100 & 1000 & 0 & 0 \\
\hline Gonyaulax & 0 & 0 & 100 & 0 & 0 \\
\hline $\begin{array}{l}\text { Scrippsiella }+ \text { Ensiculifera }+ \text { Pentapharsodinium } \\
+ \text { Bysmatrum }\end{array}$ & 0 & 200 & 2,600 & 1,000 & 1,800 \\
\hline Torodinium & 0 & 0 & 100 & 100 & 200 \\
\hline Amphidinium & 0 & 0 & 0 & 200 & 0 \\
\hline Heterocapsa triquetra & 0 & 0 & 200 & 0 & 0 \\
\hline Peridiniales & 400 & 0 & 0 & 1,200 & 1,000 \\
\hline Peridiniaceae & 0 & 0 & 1,400 & 0 & 0 \\
\hline Peridinium quinquecorne & 0 & 400 & 3,200 & 0 & 0 \\
\hline Euglena & $\mathbf{1 A}$ & $\mathbf{2 A}$ & 3A & $4 \mathrm{~A}$ & 6A \\
\hline Euglenaceae & 0 & 600 & 400 & 0 & 0 \\
\hline Eutreptiaceae & 0 & 0 & 0 & 2,200 & 0 \\
\hline Eutreptiella & 2,400 & 5,000 & 4,000 & 0 & 3,600 \\
\hline Cryptomonads & $\mathbf{1 A}$ & $2 \mathrm{~A}$ & 3A & $4 \mathrm{~A}$ & $6 \mathrm{~A}$ \\
\hline Cryptomonadales & 50,700 & 331,500 & 181,400 & 194,100 & 36,400 \\
\hline Diatoms & $\mathbf{1 A}$ & 2A & 3A & $4 \mathrm{~A}$ & 6A \\
\hline Centrales & 0 & 0 & 0 & 0 & 400 \\
\hline Rhizosolenia imbricata + styliformis & 0 & 100 & 0 & 0 & 0 \\
\hline Rhizosolenia setigera + pungens & 0 & 0 & 0 & 600 & 1000 \\
\hline Proboscia alata & 0 & 100 & 0 & 0 & 0 \\
\hline
\end{tabular}


Table S1. Cont.

\begin{tabular}{|c|c|c|c|c|c|}
\hline Corethron & 0 & 0 & 0 & 100 & 0 \\
\hline Paralia sulcata & 600 & 0 & 0 & 400 & 0 \\
\hline Thalassiosira & 0 & 0 & 0 & 2,400 & 7,000 \\
\hline Thalassiosira rotula & 0 & 0 & 0 & 0 & 400 \\
\hline Corethron & 0 & 0 & 0 & 0 & 1,200 \\
\hline Chaetoceros & 56,200 & $1,821,400$ & 627,900 & 0 & 13,400 \\
\hline Chaetoceros decipiens & 2,800 & 19,800 & 1,200 & 3,200 & 6,800 \\
\hline Chaetoceros curvisetus + debilis + pseudocurvisetus & 0 & 0 & 0 & 1200 & 19,800 \\
\hline Chaetoceros danicus & 0 & 0 & 0 & 0 & 600 \\
\hline Lithodesmium & 200 & 5,300 & 7,000 & 3,600 & 6,800 \\
\hline Leptocylindrus danicus & 6,200 & 1,600 & 0 & 3,800 & 12,200 \\
\hline Leptocylindrus minimus & 0 & 4,800 & 0 & 0 & 6200 \\
\hline Cerataulina pelagica & 400 & 1,000 & & 5,400 & 2,800 \\
\hline Dactyliosolen fragilissimus & 1,000 & 4,600 & 1200 & 1,000 & 4,400 \\
\hline Guinardia striata & 1,100 & 0 & 0 & 0 & 1,800 \\
\hline Guinardia flaccida & 100 & 0 & 0 & 0 & 0 \\
\hline Guinardia delicatula & 0 & 0 & 0 & 0 & 1,400 \\
\hline Skeletonema costatum & 0 & 3,600 & 500 & 0 & 1,000 \\
\hline Odontella regia & 0 & 0 & 0 & 0 & 600 \\
\hline Biddulphia alternans & 0 & 0 & 0 & 0 & 600 \\
\hline Eucampia zodiacus & 0 & 0 & 0 & 0 & 1,400 \\
\hline Hemiaulus & 400 & 1,100 & 0 & 0 & 0 \\
\hline Lauderia & 400 & 0 & 0 & 0 & 0 \\
\hline Pennales & 3,800 & 600 & 200 & 2,000 & 4,200 \\
\hline $\begin{array}{l}* \text { Pseudo-nitzschia large width, seriata complex } \\
(\text { australis }+ \text { fraudulenta }+ \text { seriata }+ \text { subpacifica })\end{array}$ & 30,200 & 200 & 0 & 0 & 0 \\
\hline $\begin{array}{l}* \text { Pseudo-nitzschia narrow width, delicatissima } \\
\text { complex (calliantha }+ \text { delicatissima }+ \\
\text { pseudodelicatissima })\end{array}$ & 0 & 6,800 & 0 & 0 & 0 \\
\hline $\begin{array}{l}\text { * Pseudo-nitzschi, slender group, seriata complex } \\
\text { (multiseries }+ \text { pungens })\end{array}$ & 0 & 0 & 0 & 0 & 800 \\
\hline * Pseudo-nitzschia sigmoid group (multistriata) & 0 & 0 & 400 & 1,700 & 40,600 \\
\hline Thalassionema nitzschioides & 0 & 2,200 & 0 & 1,200 & 12,600 \\
\hline Pleurosigma + Gyrosigma & 0 & 0 & 100 & 600 & 600 \\
\hline Nitzschia & 0 & 0 & 0 & $\begin{array}{l}1,100 \\
0\end{array}$ & 72,800 \\
\hline Nitzschia longissima & 1200 & 400 & 600 & 0 & 400 \\
\hline Cylindrotheca closterium & 6,600 & 16,400 & 25,350 & 0 & 2,600 \\
\hline Asterionellopsis glacialis & 19,000 & 32,400 & 0 & $\begin{array}{l}2,780 \\
0\end{array}$ & 446,400 \\
\hline Licmophora & 0 & 0 & 0 & 100 & 0 \\
\hline Cocconeis & 0 & 0 & 0 & 400 & 200 \\
\hline Heterokonts & $\mathbf{1 A}$ & 2A & 3A & 4A & 6A \\
\hline *Heterosigma akashiwo & 0 & 0 & 0 & 600 & 400 \\
\hline Dictyocha & 0 & 0 & 100 & 400 & 200 \\
\hline
\end{tabular}


Table S2. Mean of the total signal intensity (TI) and its standard deviation (STDEV) of each microarray-probe used in the graphs of the publication.

\begin{tabular}{|c|c|c|c|c|c|c|c|c|c|c|}
\hline & \multicolumn{2}{|c|}{ 1A $(24.07 .2011)$} & \multicolumn{2}{|c|}{ 2A (08.08.2011) } & \multicolumn{2}{|c|}{ 3A (22.08.2011) } & \multicolumn{2}{|c|}{ 4A $(04.10 .2011)$} & \multicolumn{2}{|c|}{ 6A $(20.10 .2011)$} \\
\hline & $\mathrm{TI}$ & STDEV & TI & STDEV & $\mathrm{TI}$ & STDEV & TI & STDEV & TI & STDEV \\
\hline PSN + some Frags_25_dT & 571,661 & 283,278 & 462,375 & 261,002 & 376,328 & 136,949 & 328,723 & 64,836 & $1,234,899$ & 246,612 \\
\hline PSN+FRAGS02-25new_dT & 570,012 & 278,217 & 483,590 & 235,672 & 374,378 & 107,819 & 328,689 & 73,975 & $1,236,907$ & 237,510 \\
\hline PsnGS02_25_dT & 366,160 & 122,407 & 269,644 & 59,512 & 176,231 & 40,406 & 154,926 & 102,545 & 527,093 & 47,698 \\
\hline PmulacalD02_25_dT & 201,918 & 30,724 & 189,923 & 53,609 & 35,294 & 18,226 & 35,985 & 14,234 & 253,037 & 27,753 \\
\hline PmulaD03_25_dT & 66,635 & 5,760 & 71,895 & 9,951 & 37,380 & 15,172 & 18,590 & 10,183 & 212,033 & 22,236 \\
\hline PmulausD01_25_dT & 240,310 & 36,151 & 168,879 & 19,588 & 154,874 & 31,009 & 181,673 & 30,966 & 784,727 & 91,653 \\
\hline ProroFPS01 & 169,269 & 31,916 & 160,601 & 35,392 & 58,362 & 14,735 & & & 78,983 & 19,111 \\
\hline ProroFBS01 & & & & & & & 113,540 & 137,560 & 67,434 & 189,17 \\
\hline PrathD01 & & & & & & & & & 108,027 & 8,344 \\
\hline PbeliS01 & & & & & & & 60,137 & 58,069 & 21,412 & 24,719 \\
\hline AlexGD01_25_dT & 477,054 & 82,900 & 555,744 & 276,647 & 270,780 & 352,356 & 154,715 & 37,017 & 389,966 & 29,238 \\
\hline PschGS01_25_dT & & & & & & & & & 63,769 & 9,284 \\
\hline PschGS04_25_dT & & & & & & & & & 547,515 & 98,442 \\
\hline PschGS05_25_dT & & & & & & & & & 47,371 & 12,185 \\
\hline PverD01_25_dT & & & & & & & & & 70,207 & 10,052 \\
\hline PfarD01_25_dT & & & & & & & & & 51,096 & 8,260 \\
\hline PrymS01_25_dT & $1,062,712$ & 223,123 & $1,208,456$ & 400,071 & $1,285,690$ & 372,848 & $1,592,062$ & 501,853 & $1,127,413$ & 97,605 \\
\hline PrymS03_25_dT & 184,896 & 64,536 & 262,141 & 132,584 & 204,940 & 51,019 & 231,062 & 63,987 & 285,495 & 49,415 \\
\hline Clade01old_25_dT & 935,860 & 146,759 & 707,441 & 135,777 & 487,530 & 194,120 & 521,791 & 172,448 & 353,814 & 29,352 \\
\hline Clade 01new25_dt & & & & & 217,043 & 82,294 & 293,107 & 86,528 & 141,925 & 34,971 \\
\hline CpolyS01_25_dT & & & & & & & 112,327 & 9,400 & 122,730 & 29,900 \\
\hline PparvD01_25_dT & & & & & & & 133,275 & 251,500 & & \\
\hline KargeD01_25_dT & & & & & 138,096 & 195,135 & 90,368 & 92,796 & 17,867 & 11,278 \\
\hline
\end{tabular}

(C) 2013 by the authors; licensee MDPI, Basel, Switzerland. This article is an open access article distributed under the terms and conditions of the Creative Commons Attribution license (http://creativecommons.org/licenses/by/3.0/). 